\title{
Systemic polyarteritis nodosa
}

INSERM

\section{Source}

INSERM. (1999). Orphanet: an online rare disease and orphan drug data base. Systemic polyarteritis nodosa. ORPHA:439762

Systemic polyarteritis nodosa (PAN; see this term) is a chronic systemic necrotizingvasculitis of adults and childrenaffecting small- and medium-sized vessels and characterized by formation of microaneurysms leading to serious generalized disease and multi-org an involvement. 